\title{
A GREEN STRATEGY TO SYNTHESIZE ENVIRONMENT FRIENDLY METAL OXIDE NANOPARTICLES FOR POTENTIAL APPLICATIONS: A REVIEW
}

\author{
VANI P, MANIKANDAN N, VINITHA G* \\ Department of Physics, School of Advanced Sciences, VIT University, Chennai, Tamil Nadu, India. Email: vinitha.g@vit.ac.in
}

Received: 23 January 2017, Revised and Accepted: 03 March 2017

\begin{abstract}
Chemical-reducing and capping reagents are widely used in synthesizing metal oxide nanoparticles (NPs) which limit the biomedical applications. Researchers have recently found the eco-friendly technique of green synthesis which enhances the unique physical and chemical properties of nanomaterials. In this critique, we discuss green route to synthesize metal oxide NPs and its significant applications in various fields of energy and environment, aerospace, medicine, biotechnology, etc. This study arouses to provoke new research design of approach to synthesize NPs for various technological applications. In this review, most of the metal oxide NPs and different plant extracts with enhanced properties for their potential applications are discussed which confirms plant extracts as a potential candidate to be used as a reducing and capping agent.
\end{abstract}

Keywords: Green synthesis, Metal oxides, Reducing agent, Capping agent, Plant extract.

(C) 2017 The Authors. Published by Innovare Academic Sciences Pvt Ltd. This is an open access article under the CC BY license (http://creativecommons. org/licenses/by/4. 0/) DOI: http://dx.doi.org/10.22159/ajpcr.2017.v10s1.19751

\section{INTRODUCTION}

Nanomaterials are materials having nanometer scale at least in one dimension which results in significant change in properties which can be employed for different applications.

The nanomaterials have high surface-to-volume ratio and quantum confinement effect. Nanotechnology is the configuration of functional materials, devices, and systems through working at the atomic, molecular, and supra-molecular levels in the scale of approximately 1-100 $\mathrm{nm}$ range. By controlling and manipulating the nanomaterials, one can achieve enhanced unique physical, chemical, and magnetic properties compared to bulk materials. Nanoscience and nanotechnology span many areas such as information technology, energy, and environment, aerospace, medicine, and biotechnology. Metal oxide nanoparticles (NPs) are synthesized for a wide variety of applications including electronic, magnetic, and optoelectronic devices. Controlling the size of the NPs is the major parameter for a variety of applications. Metal oxides can be synthesized by chemical methods such as sol-gel [1], hydrothermal [2], microwave [3], coprecipitation [4], sonochemical [5], solvothermal [6], and laser ablation method [7]. In the conventional methods, chemicals such as hydrazine monohydrate [8], cetyltrimethyl ammonium bromide [8], and polyvinyl pyrrolidone (PVP) [9] are used as reducing reagent and capping agent. It leads to toxicity and is potentially hazardous. It needs high temperature and high pressure for synthesis. It also involves expensive precursors. Use of chemicals as reducing and capping agent also limits the applications, in particular biomedical application.

\section{GREEN TECHNOLOGY}

To overcome the limitations and disadvantages of chemical synthesis, green technology was introduced. Green technology is a way to synthesize NPs with high potential properties and is helpful to overcome the limitations of applications in several fields. It is more advantageous over chemical synthesis. It is free from toxic solvents, does not require expensive equipment, and is cost effective. The main goal of green synthesis is to synthesize NPs with lesser cost and to reduce chemical wastes.

\section{Advantages of green technology}

- Less toxic

- $\quad$ Cost-effective
- Environmental friendly

- Better applications

To synthesize environmental friendly NPs, various entities are used. Algae [10], bacteria [11,12], fungi [13], and plant [14] entities are used in green synthesis to achieve unique physical and chemical properties of nanomaterials. Fig. 1 shows the biosynthesis flow chart of metal oxide NPs. Synthesis of metal oxide NPs using plant entities such as root [15], flower [16], stem, leaves [17], and fruit [18] is reviewed in this article. The role of naturally found capping and reducing agent shows the biocompatibility of synthesized NPs [19]. Moreover, the significant role of plants in different applications has been discussed.

\section{VARIOUS BIOACTIVE COMPOUNDS PRESENT IN BIOSYNTHESIS}

Usually, metal oxide NPs are synthesized using top-down and bottomup approaches. Recent research introduces biosynthesis as a nontoxic and environmental friendly method over the other approaches. Biosynthesis yields positive aspects over several applications, especially in the field of medicine. Researchers have reported on biosynthesis, mycosynthesis, and its various applications.

Using plant parts to synthesize NPs is known as biosynthesis. Using microorganisms to synthesize NPs is known as mycosynthesis. Plant extracts act as a reducing and capping agent, give stability to the NPs, and help to increase the rate of reduction [20]. However, the reasons for extracts to act as reducing and capping agent and the actual mechanism of synthesis are yet to be explored. Different plants contain different bioactive compounds which act as reducing and capping agents to reduce metal ions. They contain a number of compounds such as amino acids, anthraquinones, enzymes, minerals, vitamins, lignins, monosaccharides, polysaccharides, salicylic acids, saponins, and sterols.

\section{Cerium oxide}

Polysaccharides play an important role in encapsulating cerium ions. Gloriosa superba belonging to Colchicaceae family has alkaloids acting as a reducing agent. Each part of the plant extract has various kinds of bimolecular compounds necessary for biomedical applications $[21,22]$.

\section{Cobalt oxide}

Calotropis gigantea belonging to Asclepiadaceae family contains phytochemical constituents which play a nontoxic reducing as well as 


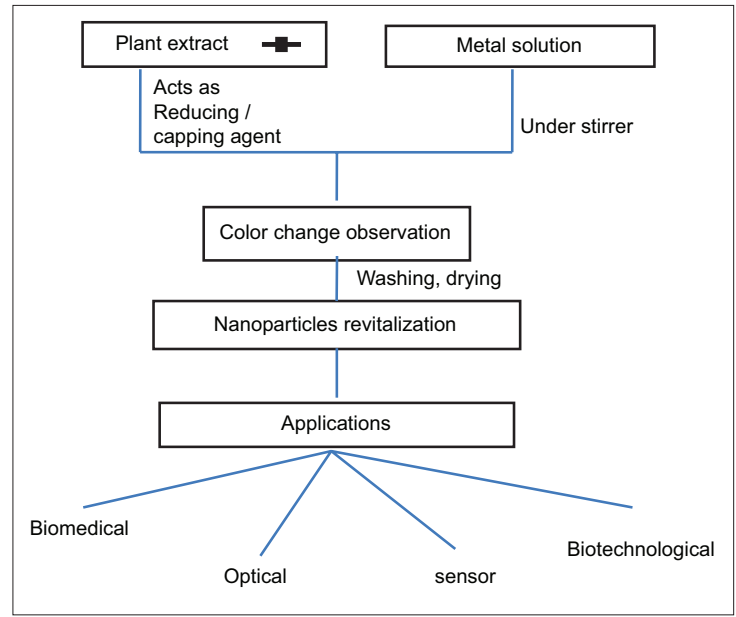

Fig. 1: Flow chart for synthesis of metal oxide nanoparticles using plant extracts

capping agent role in controlling the size and morphology of the NPs for various different applications [23]. Aspalathus linearis plant extract has two major phenolic compounds as aspalathin (a dihydrochalcone C-glucoside), and aspalalinin (a cyclic dihydrochalcone) which act as reducing agents. The most important bioactive compounds to reduce metal ion is present in Aspalathus linearis which belongs to (rooibos) Fabaceae family [24].

\section{Graphene oxide (GO)}

Polyphenols, flavonoids, and catechins are important phytochemical constituents found in the grape extract which mainly plays a role in reducing bulk gold and silver metals. This extract acts as a selective reduction agent, especially in reducing ketone and nitro compounds [25]. Phenols present in Terminalia chebula act as good reducing agent stabilizing the metal ions [26].

\section{Iron oxide}

Polyphenols present in Acacia mearnsii, in particular, quinones, act as reducing unit to reduce $\mathrm{Fe}^{3+}$ to $\mathrm{Fe}^{0}$ as well as capping and stabilizing agent [27]. Tangerine peel extract acts as surfactant and stabilizer for synthesized iron oxide NPs [28]. Caricaya papaya leaf extracts and Aloe vera extracts are used to synthesize iron oxide NPs $[29,30]$.

\section{Magnesium oxide}

Citrus lime acts as a dispersing and capping agent and neem leaves act as reducing agent [31,32]. Acacia gum is a good adsorbent having anionic nature, it contains charged groups such as polysaccharides, protein, and arabinose-galactose protein species which increases the adsorption efficiency [33].

\section{Ruthenium oxide}

Acalypha indica, which belongs to the family Euphorbiaceae, contains alkaloids such as acalyphamide which is used as a reducing agent [34].

\section{Titanium dioxide}

Aeromonas hydrophila contains glycyl-L-proline of A. hydrophila which possesses reducing, capping, and stabilizing capabilities [35]. Albizia saman belongs to Fabaceae family. It acts as a reducing agent [36]. Cinnamomum tamala belongs to the family Lauraceae. Terpenoids, flavonoids, sterols, saponins, amino acid, and polyphenols are responsible for the reduction of $\mathrm{Au}^{3+}$ to $\mathrm{Au}^{0}$. This extract acts as reducing as well as a capping agent for NPs [37]. Hibiscus flower acts as a stabilizing agent because it is found to have enough amount of polyphenols such as tannins and proteins [38] Euphorbia heteradena Jaub root belongs to Euphorbia family. It has special biomolecular compounds such as aromatic esters, terpenoids, saponins, and steroids. Root extract of this plant is used as a reducing and stabilizing agent [15]. Nyctanthes arbor-tristis leaves are rich in phytochemicals which act as a solvent medium, reducing as well as stabilizing agent [39].
Copper oxide (CuO)

A. indica which acts as both reducing and capping agent belongs to Euphorbiaceae family [40]. Aloe barbadensis belongs to the Liliaceae family. It has 75 active constituents. Among these, vitamins, enzymes, minerals, sugars, salicylic acids, lignins, saponins, and amino acids act as a reducing and capping agent [41]. Andean blackberry is commonly known as Rubus glaucus Benth. Its fruit and leaf contains phenolic composition which consists of ellagitannins and anthocyanins. Mainly, its leaves are rich in flavonoids, allagic, and tannins [42]. C. gigantea belongs to the Asclepiadaceae family. Phenols present in the extract act as reducing and capping agent [43]. Citrus lime juice acts as a good bioreductant. As reported in literature, PVP acts as a stabilizer [44]. Both Anthemis nobilis flowers and Gundelia tournefortii belong to Asteraceae family. Both have good reducing and stabilizing capabilities [45,46]. Tinospora cordifolia belongs to Menispermaceae family. It contains alkaloids, diterpenoids, lactones, glycosides, steroids, sesquiterpenoids, phenolics, aliphatic compounds, and polysaccharides. Various components present in leaves are antioxidants and may act as good fuels for the preparation of NPs [47]. Euphorbia esula L. has important phytochemicals such as terpenoids, flavonoids, phenolic acids, tannins, and sterols which help to reduce and stabilize the NPs [48]. Tabernaemontana divaricates leaf belongs to Apocynaceae family. It contains phytochemicals such as alkaloids, tannins, flavonoids, phytosterols, phenols, terpenes, and carbohydrates [49]. Theobroma cacao L. seeds belonging to Sterculiaceae family have bioactive compounds such as powerful flavonols and antioxidants as either the monomers or oligomers which act as capping agent and deter the aggregation of NPs [50].

\section{Zinc oxide (ZNO)}

Anisochilus carnosus leaf extract belongs to Lamiaceae family. Active components present in the extracts are alkaloids, tannins, flavonoids, and phenolic compounds [51]. Artocarpus gomezianus fruit extract acts as fuel and belongs to the family of Moraceae. It is rich in phenolic compounds which have high reducing properties to reduce nitrides into their metallic form NPs in combustion method [52]. Murraya koenigii belongs to Rutaceae family. Its leaves, bark, and the base are used. The main functional groups present in the plant are polyphenols (gallic acid) and flavonoids (quercetin) which help to stabilize (deter agglomeration) the NPs [53]. Garcinia xanthochymus fruit extract, rich in polyphenols, acts as reducing agent and acts as a source of fuels to reduce nitrides into their metallic form [54]. Green tea is rich in flavonoids and catechins which are very good reducers, stabilizers, and inhibit the growth of agglomeration [55]. Moringa oleifera belongs to Moringaceae. It has a good source of natural oxidants such as flavonoids, phenolics, and carotenoids. Every part of the plant is used to synthesize NPs [56]. Plectranthus amboinicus leaf extract belonging to Lamiaceae family acts as a reducing agent for gold NPs [57]. Pongamia pinnata has biological active compounds to stabilize the NPs [17]. Citrus aurantifolia has different bioactive compounds responsible for capping and stabilization of metal ions [58]. The synthesis of environmentally friendly metal oxide NPs with the role of plant extract is shown in Table 1.

\section{TO OBTAIN NPS THROUGH GREEN SYNTHESIS ROUTE}

The gel of $A$. vera leaves was scraped off and added to the precursor of cerium nitrate hexahydrate compound. After that, the reaction mixture was kept under continuous stirring. Then, it is dried in the hot plate and a fine powder was obtained.

The obtained powder was calcinated at $600^{\circ} \mathrm{C}$ [21]. Finely cut leaves were added into double-distilled water and boiled at 50$60^{\circ} \mathrm{C}$ for 5 minutes. The extract was filtered using Whatman filter paper. The extract was added into cerium chloride under constant stirring at the temperature of $80^{\circ} \mathrm{C}$ for $4-6 \mathrm{hrs}$. A white precipitate was obtained and it changed to yellowish brown on continuous stirring. The obtained precipitate was calcined at $400^{\circ} \mathrm{C}$ for 2 hrs [22]. A. linearis leaves were added into deionized water at a temperature between $75^{\circ} \mathrm{C}$ and $85^{\circ} \mathrm{C}$ for $2-3$ hrs yielding a brown 
Table 1: Role of plant extracts on synthesis of metal oxide nanoparticles

\begin{tabular}{|c|c|c|c|c|c|}
\hline S. No & Plant extract & Family & Bioactive compounds & $\mathrm{R} / \mathrm{C} / \mathrm{S}$ & Ref. No \\
\hline 1. & Gloriosa superba & Colchicaceae & Alkaloids & Reducing agent & {$[21,22]$} \\
\hline 2. & Calotropis gigantea & Asclepiadaceae & Bimolecular compounds & Reducing and capping agents & [23] \\
\hline 3. & Aspalathus linearis & Fabaceae & $\begin{array}{l}\text { Phenolic compounds (palalin } \\
\text { and aspalalin) }\end{array}$ & Reducing agent & {$[24]$} \\
\hline 4. & Grape extract & Vitaceae & $\begin{array}{l}\text { Polyphenols, flavonoids, and } \\
\text { catechins }\end{array}$ & $\begin{array}{l}\text { Reducing (gold and silver), } \\
\text { and selective reducing agent to } \\
\text { ketone and nitro compounds }\end{array}$ & {$[25]$} \\
\hline 6. & Acacia mearnsii & Legumes & Quinones (polyphenol unit) & $\begin{array}{l}\text { Reducing and stabilizing } \\
\text { agent }\left(\mathrm{Fe}^{3+} \text { to } \mathrm{Fe}^{0}\right)\end{array}$ & [27] \\
\hline 7. & Tangerine peel & Rutaceae & Biomolecules & Surfactant and stabilizing agent & [28] \\
\hline 8. & Caricaya papaya and Aloe vera & $\begin{array}{l}\text { Caricaceae } \\
\text { Xanthorrhoeaceae }\end{array}$ & Biomolecules & Reducing agent & {$[29,30]$} \\
\hline 9. & $\begin{array}{l}\text { Citrus lime } \\
\text { Neem leaves }\end{array}$ & $\begin{array}{l}\text { Rutaceae } \\
\text { Meliaceae }\end{array}$ & Biomolecules & - & {$[31,32]$} \\
\hline 10. & Acacia gum & Fabaceae & $\begin{array}{l}\text { Polysaccharides, protein, and } \\
\text { arabinose-galactose protein } \\
\text { species }\end{array}$ & Good adsorbent & {$[33]$} \\
\hline 11. & Aeromonas hydrophila & Pseudomonadaceae & Glycyl L-proline & $\begin{array}{l}\text { Reducing, capping, and } \\
\text { stabilizing agent }\end{array}$ & {$[35]$} \\
\hline 12. & Albizia saman & Fabaceae & - & Reducing agent & [36] \\
\hline 13. & Cinnamomum tamala & Lauraceae & $\begin{array}{l}\text { Terpenoids, flavonoids, sterols, } \\
\text { saponins, amino acid }\end{array}$ & Capping agent & {$[37]$} \\
\hline 14. & Hibiscus flower & Malvaceae & Tannins, proteins & Stabilizing agent & {$[38]$} \\
\hline 15. & Euphorbia heteradena Jaub root & Euphorbiaceae & $\begin{array}{l}\text { Aromatic esters, terpenoids, } \\
\text { saponins, and steroids }\end{array}$ & Reducing and stabilizing agent & {$[15]$} \\
\hline 16. & Nyctanthes arbor-tristis & Oleaceae & Phytochemicals & $\begin{array}{l}\text { Solvent medium, reducing, and } \\
\text { stabilizing agent }\end{array}$ & [39] \\
\hline 17. & Acalypha indica & Euphorbiaceae & Biomolecules & Reducing and capping agent & {$[40]$} \\
\hline 18. & Aloe barbadensis & Liliaceae & $\begin{array}{l}\text { Vitamins, enzymes, minerals, } \\
\text { sugars, salicylic acids, lignins, } \\
\text { saponins, amino acids }\end{array}$ & Reducing and capping agent & {$[41]$} \\
\hline 19. & Andean blackberry & Rusaceae & $\begin{array}{l}\text { Ellagitannins and } \\
\text { anthocyanins, flavonoids, } \\
\text { allagic, and tannins }\end{array}$ & -5 & {$[42]$} \\
\hline 20. & Calotropis gigantea & Asclepiadaceae & Phenols & Reducing and capping agent & {$[43]$} \\
\hline 21. & Citrus lime juice & Rutaceae & Biomolecules & Bioreductant & [44] \\
\hline 22. & $\begin{array}{l}\text { Anthemis nobilis } \\
\text { Gundelia tournefortii }\end{array}$ & Asteraceae & Biomolecules & Reducing and stabilizing agent & {$[45,46]$} \\
\hline 23. & Tinospora cordifolia & Menispermaceae & $\begin{array}{l}\text { Alkaloids, diterpenoid, } \\
\text { lactones, glycosides, steroids, } \\
\text { sesquiterpenoid, aliphatic, and } \\
\text { polysaccharides }\end{array}$ & Antioxidant, act as a good fuel & {$[47]$} \\
\hline 24. & Euphorbia esula L. & Euphorbiaceae & $\begin{array}{l}\text { Terpenoids, flavonoids, } \\
\text { phenolic acids, tannins, and } \\
\text { sterols }\end{array}$ & Reducing and stabilizing agent & {$[48]$} \\
\hline 25. & Tabernaemontana divaricate & Apocynaceae & $\begin{array}{l}\text { Alkaloids, tannins, flavonoids, } \\
\text { phytosterols, phenols, } \\
\text { terpenes, and carbohydrates }\end{array}$ & - & [49] \\
\hline 26. & Theobroma cacao L. & Sterculiaceae & $\begin{array}{l}\text { Bioactive compounds, flavonol } \\
\text { either monomers or oligomers }\end{array}$ & $\begin{array}{l}\text { Capping agent and deter the } \\
\text { agglomeration }\end{array}$ & {$[50]$} \\
\hline 27. & Anisochilus carnosus & Lamiaceae & $\begin{array}{l}\text { Alkaloids, tannins, flavonoids, } \\
\text { and phenolic compounds }\end{array}$ & - & {$[51]$} \\
\hline 28. & Artocarpus gomezianus & Moraceae & Phenolic compound & Reducing agent & {$[52]$} \\
\hline 29. & Murraya koenigii & Rutaceae & $\begin{array}{l}\text { Gallic acid (polyphenols) and } \\
\text { flavonoids (quercetin) }\end{array}$ & Stabilizing agent & [53] \\
\hline 30. & Garcinia xanthochymus & Clusiaceae & Polyphenols & Reducing agent & {$[54]$} \\
\hline 31. & Green tea & Theaceae & Flavonoids and catechins & Capping and reducing agent & [55] \\
\hline 32. & Moringa oleifera & Moringaceae & $\begin{array}{l}\text { Flavonoids, phenolics, and } \\
\text { carotenoids }\end{array}$ & - & {$[56]$} \\
\hline 33. & Plectranthus amboinicus & Lamiaceae & Biomolecules & $\begin{array}{l}\text { Reducing agent for gold } \\
\text { nanoparticles }\end{array}$ & {$[57]$} \\
\hline 34. & Citrus aurantifolia & Rutaceae & Bioactive compounds & Capping and stabilizing agent & {$[58]$} \\
\hline 35. & Pongamia pinnata & Fabaceae & Bioactive compounds & Stabilizing agent & [17] \\
\hline
\end{tabular}

extract $(\mathrm{pH}=5)$. The filtered solution was added into cobalt nitrate hexahydrate $(\mathrm{pH}=3.8)$. It was kept under a stirrer. The mixture was allowed to settle over a period of $24 \mathrm{hrs}$, without any heating. It was centrifuged at $1000 \mathrm{rpm} 3$ times for 10 minutes. It was annealed at different temperatures [24]. T. chebula plant seeds were dried under sunlight and they were ground into fine powder. The powder 
was heated about $90^{\circ} \mathrm{C}$ and cooled, filtered through cellulose nitrate membrane filter paper. Using $\mathrm{NH}_{4} \mathrm{OH}, \mathrm{PH}$ was adjusted to 12 . The resultant mixture was refluxed on a water bath at $90^{\circ} \mathrm{C}$ for about 24 hrs. Reduction was observed through the color change of the solution from yellowish brown to black [26]. Titanium oxysulfate was added to hibiscus flower extract under continuous stirring. PH was adjusted to 7 . The NPs were centrifuged at $8000 \mathrm{rpm}$, and the titanium oxide NPs were obtained [38]. A. vera leaf was added into copper sulfate under a magnetic stirrer. Under continuous magnetic stirring at $130^{\circ} \mathrm{C}$ for $7 \mathrm{hrs}$, the precipitate was obtained. The obtained precipitate was centrifuged twice at $3500 \mathrm{rpm}$ for 20 minutes and dried at $120^{\circ} \mathrm{C}$ for $6 \mathrm{hrs}$. The final product was crushed into powder for further characterizations [41]. Fresh leaves of $C$. gigantea plant were washed with double-distilled water and then sun dried to remove the residual moisture. Dried, fine-cut leaves were added to deionized water and boiled for 60 minutes until the color of the aqueous solution changed from Watery colour to light yellow colour. The mixture was then filtered to obtain aqueous leaf extract. A certain amount of $C$. gigantea leaf extract was taken and boiled to $60-80^{\circ} \mathrm{C}$ using a stirrer-heater. Cupric nitrate was added to the solution and then boiled until it reduced to a deep yellow color paste. This paste was then collected in a ceramic crucible and heated in an air-heated furnace at $400^{\circ} \mathrm{C}$ for $2 \mathrm{hrs}$.

Black CuO NPs were obtained [43]. Lemon juice was extracted from fresh lemons and centrifuged at $8000 \times g$ for 10 minutes to separate any solid matter from it. Then, lemon extract and polyvinylpyrrolidone solution were mixed. The PVP and lemon extract mixture were then added into copper acetate monohydrate $\left(\mathrm{Cu}\left(\mathrm{CH}_{3} \mathrm{COO}\right)_{2} \bullet \mathrm{H}_{2} \mathrm{O}\right)$. The boiling solution was kept at a stirring speed of $600 \mathrm{rpm}$ and $110^{\circ} \mathrm{C}$ under stirring condition and was maintained until the color of the solution changed from bluish green to orange. The obtained residue of cuprous oxide NPs ( $\mathrm{Cu}_{2}$ ONPs) was collected by centrifugation at 5000 $\times g$ for 10 minutes and was repeatedly washed with deionized doubledistilled water, ethanol, and acetone. The collected mass was further annealed at $500^{\circ} \mathrm{C}$ for $2 \mathrm{hrs}$ in a furnace to achieve highly crystalline and stable cupric oxide NPs [44]. Dried aerial parts of $A$. nobilis flowers were powdered and refluxed at $80^{\circ} \mathrm{C}$ with sterile distilled water. Then, the mixture was allowed to cool to room temperature, and the aqueous extract was easily obtained by filtration. The aqueous extract was added drop wise into $\mathrm{cucl}_{2}$ with constant stirring at $60^{\circ} \mathrm{C}$ for 2 hrs. Then, the color change was observed during the heating process due to excitation of surface plasmon resonance which indicates the formation of CuO NPs. The obtained solution of NPs was centrifuged at $6500 \mathrm{rpm}$ for 30 minutes and precipitation was then air-dried for $24 \mathrm{~h}$ at room temperature [45]. Green tea leaf powder was added to distilled water and kept under a magnetic stirrer for $2 \mathrm{hrs}$ at $80^{\circ} \mathrm{C}$. After cooling to room temperature and filtering through Whatman No. 1 paper, this green tea extract was mixed homogeneously with the already prepared zinc acetate solution. The reacted solution was dried at $60^{\circ} \mathrm{C}$ overnight to yield pale-white ZnO NPs, which were finally calcined at $100^{\circ} \mathrm{C}$ for $1 \mathrm{hr}$ and preserved in air-tight vials for further studies [55]. C. aurantifolia fruit pulps were sliced into small pieces and blended in distilled water. The blended pulps were then filtered using a muslin cloth to remove solid particles. $C$. aurantifolia liquid extracts were added into zinc acetate solution. The $\mathrm{pH}$ value of the solution was between 3.7 and 4.0 . The mixtures were heated at $90^{\circ} \mathrm{C}$ under continuous stirring for $3 \mathrm{~h}$ after which white precipitate occurred. The precipitates were recovered, thoroughly rinsed in deionized water, and dried at $100^{\circ} \mathrm{C}$ for $6 \mathrm{hrs}$ [58].

\section{RESULTS AND DISCUSSION}

The article reports the formation of metal oxide NPs using various plant extracts. Biosynthesis of metal oxide NPs was characterized using X-ray diffraction (XRD), ultraviolet-visible spectroscopy (UV-Vis), scanning electron microscopy (SEM), transmission electron microscopy (TEM), X-ray photoemission spectroscopy, Raman spectroscopy, etc. The variously characterized results are summarized as follows.
XRD studies and SEM analysis

XRD was done using X-rays with a wavelength of $1.54 \AA$. Through XRD, the cell parameters, crystallite size, cell volume, space group, and structure of the samples are studied. Different plant extracts give different sizes of the NPs which can be used for various applications.

The average crystalline sizes of the NPs are calculated using DebyeScherrer's formula.

Average crystalline size,

$\mathrm{D}=\frac{0.9 \lambda}{\beta \cos \theta}$

where, $\lambda$ is the wavelength of X-ray used (1.54060 $\AA$ ), $\beta$ is the peak width at half maximum in radians, and $\theta$ is Bragg's diffraction. In nanotechnology, the size of particle plays an important role for potential application. Through XRD, d-space value is calculated for GO. It provides information that reduction decreases the d-spacing toward $0.850 \mathrm{~nm}$ [25]. Cerium oxide possesses face-centered structure [22], iron oxide possesses orthorhombic structure [29], and Titanium oxide possesses cubic structure. [39]. Using the plant extracts, the XRD reveals that the small size of the NPs is due to the broadening of the peaks.

As reported, the metal oxide NPs synthesized through green synthesis exhibit almost spherical which gives better application in various fields $[22,23,44,55]$. Granular-shaped NPs were obtained while they used M. oleifera as a green extract with ZNO material [56]. Citrus lime extract used with magnesium oxide preparation exhibits nanoplate morphology [31]. Likewise using iron oxide with C. papaya, nanoplates were obtained [28].

Particle size and morphology of the biosynthesized metal oxide NPs are summarized in Table 2 .

\section{Particle size analyzer}

The diameter of the metal oxide NPs was characterized by dynamic light scattering (DLS) technique. The prepared NPs were made to disperse under ultrasonication. The dispersed particles were analyzed and it was observed that the synthesized cerium oxide NPs were about $63.6 \mathrm{~nm}$ [21]. The synthesized CuO NPs using Andean blackberry leaf (ABL) and Andean blackberry fruit (ABF) extract were used. From DLS studies of CuO NPs, it was clearly shown that ABF extract ( $43.3 \mathrm{~nm}$ ) is more efficient than ABL (52.5 nm) when compared to particle size [42].

\section{UV-Vis Studies}

UV-Vis spectrophotometer allows identification, characterization, and analysis of metal oxide NPs.

In general, 200-800 $\mathrm{nm}$ light wavelength is used for characterization. The optical absorption spectra of NPs are well known to exhibit unique optical properties due to the property of surface plasmon resonance (SPR); the change in the transition of cerium ions plays an important role in the increase in the band gap of cerium oxide NPs [22]. The spectrum of GO showed that peak around at $230 \mathrm{~nm}$ and at $300 \mathrm{~nm}$ indicates the presence of GO [25]. T. chebula acting as reducing agent to reduce GO NPs showed a peak at $275 \mathrm{~nm}$ signifying the reducing efficiency of polyphenols compared to chemical reducing agents [26]. SPR peak of iron oxide NPs using C. papaya varied significantly for different concentrations of plant extract; peak at $248 \mathrm{~nm}$ indicates the presence of $\mathrm{Fe}_{3} \mathrm{O}_{4}$ [29]. For $\mathrm{TiO}_{2}$, the peaks are in the range of 200-340 $\mathrm{nm}$ [37]. The Euphorbia heterodyne root extract showed a strong absorption at 390 and $240 \mathrm{~nm}$ due to localized transition of cinnamoyl system and benzoyl system, respectively. These systems contain flavone unit which acts as the antioxidant. Biosynthesis produces more stable NPs [15]. The synthesized $\mathrm{CuO}$ Nps showed blue shift for lower concentrations of A. barbadensis extract and broadened red shift above $25 \%$ of A. barbadensis extract. For a lower concentration of extract, blue shift was observed in the spectrum. More than $25 \%$ of extract attributed to 
Table 2: Particle size and morphology of the biosynthesized metal oxide nanoparticles

\begin{tabular}{|c|c|c|c|c|}
\hline Metal oxide & Plant extract & Crystalline size (nm) & Morphology & Ref. No \\
\hline Cerium oxide & Gloriosa superba L. & 24 & Spherical & {$[22]$} \\
\hline \multirow[t]{2}{*}{ Cobalt oxide } & Calotropis gigantea & 60 & Spherical & [23] \\
\hline & Aspalathus linearis & 3.57 & Non-agglomerated quasi-spherical & [24] \\
\hline Iron oxide & Caricaya papaya & 33 & Nanoplates & [28] \\
\hline Magnesium hydroxide & Citrus lime leaf & 80 & Nanoplates & [31] \\
\hline \multirow{4}{*}{ Titanium oxide } & Aeromonas hydrophila & 40.5 & Spherical & [35] \\
\hline & Albizia saman & 41 & - & {$[36]$} \\
\hline & Hibiscus flower & 7 & Spherical & {$[38]$} \\
\hline & Nyctanthes arbor-tristis & 100 & Spherical & {$[39]$} \\
\hline \multirow[t]{4}{*}{ Copper oxide } & Acalypha indica & $26 \pm 4$ & - & {$[40]$} \\
\hline & Aloe barbadensis & 20 & Spherical & [41] \\
\hline & Andean blackberry & 43.3 & Spherical & [42] \\
\hline & Citrus lime & 9.4 & Spherical & {$[44]$} \\
\hline \multirow[t]{2}{*}{ Zinc oxide } & Artocarpus gomezianus & 11.53 & - & {$[52]$} \\
\hline & Green tea & 16 & Spherical & [55] \\
\hline
\end{tabular}

red shift which indicates the larger grain size [41]. By varying the extract of $\mathrm{ABF}$ and leaf to synthesize $\mathrm{CuO} \mathrm{NPs}$, the absorbance wavelength varied because of various constituents present in leaf and fruit. It was confirmed that peaks are at 240 and $510 \mathrm{~nm}$ due to the presence of flavonoids, ellagitannins, and anthocyanins in fruit extract. Peaks are at $240 \mathrm{~nm}$ and $360 \mathrm{~nm}$ due to the presence of flavonoids, ellagic acid, and tannins in berry leaves. The strong peak was absorbed in $250 \mathrm{~nm}$ and it was shifted to $255 \mathrm{~nm}$ due to the different composition of extracts [42]. Reduction of metal ions into metal oxide NPs during exposure to extracts was observed as a result of the color change. The color change is due to the surface plasmon resonance phenomenon. The metal NPs have free electrons, which give the SPR absorption band, due to the combined vibration of electrons of metal NPs in resonance with light wave. Anisochilus carnosus extract had a strong absorbance below $400 \mathrm{~nm}$ for different percentage of leaf extracts. The peaks are observed at 359, 354, and $349 \mathrm{~nm}$ for 30,40 , and $50 \mathrm{ml}$ of leaf extracts, respectively.

By increasing the concentration of leaf extracts, the band gaps also increased. The band energy value was calculated using the following formula:

$\mathrm{Eg}=\frac{1240}{\lambda} \mathrm{eV}$

Where, $\mathrm{Eg}$ is the band gap energy $(\mathrm{eV}), \mathrm{h}$ is Planck's constant $\left(6.626 \times 10^{-34} \mathrm{Js}\right), \mathrm{C}$ is the light velocity $\left(3 \times 10^{8} \mathrm{~m} / \mathrm{s}\right)$, and $\lambda$ is the wavelength $(\mathrm{nm})$. The increasing band gap is attributed to blue shift of optical absorption. It indicates that the synthesized ZnO NPs had smaller particle size [51].

\section{Fourier transform infrared (FTIR) studies}

FTIR spectroscopy was done within a range of $400-4000 / \mathrm{cm}$. The characterization deals the organic functional groups which are attached to the surface of NPs which are discussed as follows. The FTIR spectra of cerium oxide using G. superba contain functional groups such as - $\mathrm{C}-\mathrm{H}-$, $\mathrm{C}=\mathrm{O},-\mathrm{C}-\mathrm{H}-, \mathrm{C}-\mathrm{F}, \mathrm{C}-\mathrm{H}$, and $\mathrm{C}-\mathrm{Cl}$, which have characteristic absorptions of $1417.73 / \mathrm{cm}, 1653.03 / \mathrm{cm}, 1384.94 / \mathrm{cm}, 1151.54 / \mathrm{cm}, 879.57 / \mathrm{cm}$, and $624.96 / \mathrm{cm}$ having compounds alkane, carbonyl, alkane, alkyl halide, alkene, and alkyl halide, respectively [21]. It is evident that the FTIR spectra of cerium oxide using $G$. superba contain functional groups such as $\mathrm{O}-\mathrm{H}, \mathrm{H}-\mathrm{O}-\mathrm{H}$, and $\mathrm{Ce}-\mathrm{O}$, with characteristic absorptions such as $3750-3000 / \mathrm{cm}, 1647 / \mathrm{cm}$, and $451 / \mathrm{cm}$ which posses compounds such as residual alcohols, water, and cerium [22]. The FTIR spectra of GO using T. chebula have characteristics absorptions of 3100-3400/cm which shows that the sample containing residual alcohols exhibits $\mathrm{O}-\mathrm{H}$ bond, $\mathrm{C}=0$ contains carbonyl group at 1722 /cmabsorption, and then carboxylic (C-0) shows characteristic absorption at 1050/cm [26]. The
FTIR spectra of magnesium oxide using citrus lime showed that the functional groups of $\mathrm{O}-\mathrm{H}$ were assigned to phenol hydroxyl compound of the characteristic absorption at $3500 / \mathrm{cm}$. It is evident that $\mathrm{C}-\mathrm{O}$ group is assigned to a carboxylic compound of the characteristic absorption at $2500 / \mathrm{cm} . \mathrm{C}=\mathrm{C}$ bond is assigned to an aromatic group of the characteristic absorption at $1500 / \mathrm{cm}$. The Fe-O bond is assigned to $600 / \mathrm{cm}$ [37]. Ketones, aldehydes, and carbolic acids are assigned to C-O compound at $1635 / \mathrm{cm}$.

The C-H compounds are assigned at 2398/cm and 2082/cm belonging to aliphatic in methyl and methylene group [29]. Magnesium oxide using citrus lime FTIR spectra shows $-\mathrm{NH},-\mathrm{OH}$, and $\mathrm{C}-\mathrm{H},-\mathrm{OH}$ belonging to amino and hydroxyl groups, amide I and amide II, and surfaceadsorbed water, respectively [31]. Titanium oxide using $C$. tamala has Ti-O-Ti assignments at $1000 / \mathrm{cm} \mathrm{[37].} \mathrm{Ti-O} \mathrm{is} \mathrm{assigned} \mathrm{to} 850 / \mathrm{cm}$ and $450 / \mathrm{cm}$ for titanium oxide using hibiscus flower [38].

High-performance liquid chromatography (HPLC) analysis

HPLC is a qualitative and qualitative analysis. HPLC analysis of plant extract studies had been done to show the four different phytochemicals present in T. chebula, namely, ascorbic acid, gallic acid, pyrogallol, and methyl gallate. Further, the presence of a gallic acid as a major constituent in T. chebula extract indicates its predominant role in the reduction of GO to T. chebula-reduced graphene (TCG) [26].

\section{Raman analysis}

Raman spectrum gives the details about molecular vibrations which help to identify the phonon states of sample and its quantification.

Raman spectrum is considered to depend on:

i. Clustering of the $\mathrm{sp}^{2}$ phase;

ii. Bond disorder;

iii. Presence of $\mathrm{sp}^{2}$ rings or chains;

iv. $\mathrm{sp}^{2} / \mathrm{sp}^{3}$ ratio.

Raman active mode peak occurred at $457.24 / \mathrm{cm}$ due to asymmetrical stretching mode vibration of the Ce-80 compound [22]. The Raman mode at $684.5 / \mathrm{cm}$ is attributed to characteristics of the octahedral sites $\mathrm{A}_{1 \mathrm{~g}}$ The $\mathrm{E}_{\mathrm{g}}$, and $\mathrm{F}_{2 \mathrm{~g}}$ modes are related to the combined vibrations of a tetrahedral site and octahedral oxygen motions for cobalt oxide NPs. Due to stress/strain, the vibrational shift will occur [24]. Raman spectra of carbon have two main characteristics called $\mathrm{G}$ band and $\mathrm{D}$ band which implies $\mathrm{sp}^{2}$ hybridization. These bands occur due to the bond stretching and the bond breathing of $\mathrm{sp}^{2}$ atoms in organic compounds.

GO and TCG oxide Raman spectra are an evidence for the main characteristics of carbon materials. For graphene, the vibrational assignment peak at $1594 / \mathrm{cmindicates}$ a shift of $10 /$ cmdue to the 
bond stretching of sp2 atoms of GO from 1594/cmto 1584/cm when compared to TCG oxide. This is an evidence for the reduction of GO to graphene in the presence of T. chebula [26].

\section{TEM analysis}

Depending on the size and shape of the NPs, their physical and chemical properties are varied. Various chemical methods pursue different morphology and particle size which is most important for a wide range of applications. TEM is an important tool to analyze the morphology and particle size of the synthesized NPs. TEM examination was done for metal oxide NPs, especially adopted by green synthesis method. Different plant extracts were used to synthesize metal oxide NPs subjected to TEM analysis. These plant extracts play an important role in particle size distribution because some of the extracts act as capping agent which restricts the agglomeration. The cerium oxide NPs were prepared using $G$. superba calcined at $400^{\circ} \mathrm{C}$ and subjected to TEM analysis along with selected area electron diffraction (SAED) pattern. It shows spherical morphology and the particle size is calculated as $5 \mathrm{~nm}$. Through SAED pattern, it was confirmed that the reflections of impure crystalline were not observed [22]. Plant C. gigantea was used to synthesize cobalt oxide NPs. From the inference of TEM, it was calculated that size of the synthesized NPs ranges between 50 and $60 \mathrm{~nm}$. The NPs are almost spherical. It was noted that the plant extract act as capping agent [23]. A. linearis extract was used to synthesize cobalt oxide NPs. The size of the particle was calculated as 2-7 $\mathrm{nm}$ and in quasi-spherical shape [24]. The tannin is extracted from A. mearnsii to synthesize iron oxide NPs. The synthesized particle size was calculated using JEOLJEM-1200 EXII instrument which works at $120 \mathrm{KV}$. The average particle size is $25 \mathrm{~nm}$ which is due to the extract which acts as capping agent. [27]. A. barbadensis extract is used to synthesize $\mathrm{CuO}$ NPs. It was confirmed through TEM that the NPs are not agglomerated much because of biomolecule which is present in the leaf extract. TEM images showed that the $\mathrm{CuO}$ is surrounded by capping agent with thickness of $5 \mathrm{~nm}$ [41]. The TEM results are good in agreement with XRD results.

\section{APPLICATIONS}

Biosynthesized cerium oxide NPs show antibacterial activity against Gram-positive and Gram-negative bacteria. The result concluded that Gram-positive bacteria were relatively more susceptible compared to Gram-negative bacteria [22]. Magnesium hydroxide nanoflower was synthesized and the capability of removing divalent metallic species from synthetic waste water was studied. It was demonstrated and concluded that biosynthesized nanoflowers are capable of the removal of Co (II), Cd (II), Zn (II), Cu (II), Mn (II), Pb (II), and Ni (II) from synthetic wastewater. The capability was much faster in removing all the metallic species [33]. A. indica-mediated $\mathrm{CuO}$ NPs showed cytotoxic activity against MCF-7 breast cancer cell lines [40]. The antioxidant efficiency of $\mathrm{CuO}$ nanoparticle against 1, 1-diphenyl-2-picrylhydrazyl was studied and maximum antioxidant efficiency was noted. The effect of activity depends on the site of attachment of the metals and its consequent impact on the activity of the antioxidant agent [42]. Green-synthesized $\mathrm{CuO}$ NPs were employed as electrocatalytic materials for the fabrication of counter electrode in dye-sensitized solar cells (DSSCs) [43]. Biosynthesized $\mathrm{CuO}$ NPs showed good antibacterial activity against urinary tract pathogens (Escherichia coli) [49].

\section{CONCLUSION}

The present study discussed several important advantages over biosynthesis NPs. The synthesis method is eco-friendly and economical because it involves inexpensive and non-toxic materials. Size and shape controls of metal oxide NPs are important protocols for various applications. To achieve desired size, controlled metal oxide NPs are produced easily using different extracts as reducing and capping agents. Plant extract has a promising reducing and capping agent for metal oxides. Through this review, it has been confirmed that plants are usually found to contain significant amounts of bioactive secondary metabolites such as polyphenols. It was concluded that the phenolic compounds present in plant extracts showed higher antioxidant property which helps in the reduction process of metal ions. The content of proteins, lipids as well as amino acids helps to stabilize the NPs and deter the agglomeration [24]. Plant-mediated metal oxide NPs showed best antimicrobial and anticancer activities [40]. Biosynthesized NPs have a higher antioxidant efficiency of CuO NPs (89.02\% and 75.92\% for $1 \mathrm{mM}$ ) and it was found due to the encapsulation of phytochemicals and spherical shape [42]. Biosynthesized CuO NPs-based counter electrode exhibits reasonably good surface for the electrocatalytic activity toward the reduction of $\mathrm{I}_{3}^{-}$to $\mathrm{I}^{-}$ions in redox electrolyte, as obtained from the good reduction current. The biosynthesized CuO NPs were applied for the fabrication of efficient DSSC with high photocurrent density and high performance [43]. Using natural sunlight, the green-synthesized CuO NPs could be used as an efficient photocatalyst toward the remediation of pollution [44].

\section{REFERENCES}

1. Zhang J, Gao L. Synthesis and characterization of nanocrystalline tin oxide by sol-gel method. J Solid State Chem 2004;177(4):1425-30.

2. Ramimoghadam D, Bin Hussein MZ, Taufiq-Yap YH. Hydrothermal synthesis of zinc oxide nanoparticles using rice as soft biotemplate. Chem Cent J 2013;7:136.

3. Singh AK, Nakate UT. Microwave synthesis, characterization and photocatalytic properties of $\mathrm{SnO}_{2}$ nanoparticles. Adv Nanopart 2013;2(1):66-70.

4. Kandpal ND, Sah N, Loshali R, Joshi R, Prasad J. Coprecipitation method of synthesis and characterization of iron oxide nanoparticles. J Sci Ind Res 2014;73:87-90.

5. Guo J, Li Y, Zhu S, Chen Z, Liu Q, Zhang D, et al. Synthesis of $\mathrm{WO}_{3}$, graphene composite for enhanced photocatalytic oxygen evolution from water. RSC Adv 2012;2(4):1356-63

6. Sun C, Li H, Zhang H, Wang Z, Chen L. Controlled synthesis of $\mathrm{CeO}_{2}$ nanorods by a solvothermal method. Nanotechnology 2005;16(9):1454.

7. Boutinguiza M, Rodriguez-Gonzalez B, del Val J, Comesaña R, Lusquiños F, Pou J. Production of TiO 2 crystalline nanoparticles by laser ablation in ethanol. Appl Surf Sci 2012;258(23):9484-6.

8. Kobayashi Y, Abe Y, Maeda T, Yasuda Y, Morita T. A metal-metal bonding process using metallic copper nanoparticles produced by reduction of copper oxide nanoparticles. J Mater Res Technol 2014;3(2):114-21

9. Shahmiri M, Ibrahim NA, Faraji N, Yunus WM, Asim N, Zainuddin N. Third-order nonlinear optical properties of chemically synthesized copper oxide nanosheets. Phys E Low Dimens Sys Nanostruct 2013;54:109-14.

10. Abboud Y, Saffaj T, Chagraoui A, El Bouari A, Brouzi K, Tanane O, et al. Biosynthesis, characterization and antimicrobial activity of copper oxide nanoparticles (CONPs) produced using brown alga extract (Bifurcaria bifurcata). Appl Nanosc 2014;4(5):571-6.

11. Jha AK, Prasad K, Kulkarni AR. Synthesis of TiO 2 nanoparticles using microorganisms. Colloids Surf B Biointerfaces 2009;71(2):226-9.

12. Dhoondia $\mathrm{ZH}$, Chakraborty H. Lactobacillus mediated synthesis of silver oxide nanoparticle. Nanomater Nanotechnol 2012;2:2-15.

13. Baskar G, Chandhuru J, Fahad KS, Praveen AS. Mycological synthesis, characterization and antifungal activity of zinc oxide nanoparticles. Asian J Pharm Technol 2013;3(4):142-6.

14. Munusamy S, Bhakyaraj K, Vijayalakshmi L, Stephen A, Narayanan V. Synthesis and characterization of cerium oxide nanoparticles using Curvularia lunata and their antibacterial properties. Int J Innov Res Sci Eng 2014;129:255-8

15. Nasrollahzadeh M, Sajadi SM. Synthesis and characterization of titanium dioxide nanoparticles using Euphorbia heteradena Jaub root extract and evaluation of their stability. Ceram Int 2015;41(10):14435-9.

16. Dobrucka R, Dlugaszewska J. Biosynthesis and antibacterial activity of $\mathrm{ZnO}$ nanoparticles using Trifolium pratense flower extract. Saudi J Biol Sci 2016;23:517-23.

17. Sundrarajan M, Ambika S, Bharathi K. Plant-extract mediated synthesis of $\mathrm{ZnO}$ nanoparticles using Pongamia pinnata and their activity against pathogenic bacteria. Adv Powder Technol 2015;26(5):1294-9.

18. Ramesh P, Rajendran A, Subramanian A. Synthesis of zinc oxide nanoparticle from fruit of Citrus aurantifolia by chemical and green method. Asian J Phytomed Clin Res 2014;2(4):189-95.

19. Ambika S, Sundrarajan M. Green biosynthesis of $\mathrm{ZnO}$ nanoparticles using Vitex negundo L. extract: Spectroscopic investigation of interaction between $\mathrm{ZnO}$ nanoparticles and human serum albumin. 
J Photochem Photobiol B Biol 2015;149:143-8.

20. Bhuyan T, Mishra K, Khanuja M, Prasad R, Varma A. Biosynthesis of zinc oxide nanoparticles from Azadirachta indica for antibacterial and photocatalytic application. Mater Sci Semicond Process 2015;32:55-61.

21. Priya GS, Kanneganti A, Kumar KN, Rao KV, Bykkam S. Biosynthesis of cerium oxide nanoparticles using Aloe barbadensis miller gel. Int J Sci Res Publ 2014;4:2250-3153.

22. Arumugam A, Karthikeyan C, Hameed AS, Gopinath K, Gowri S, Karthika V. Synthesis of cerium oxide nanoparticles using Gloriosa superba L. leaf extract and their structural, optical and antibacterial properties. Mater Sci Eng C 2015;49:408-15.

23. Sharma JK, Srivastava P, Singha G, Akhtar MS, Ameen S. Green synthesis of $\mathrm{CO}_{3} \mathrm{O}_{4}$ nanoparticles and their applications in thermal decomposition of ammonium perchlorate and dye-sensitized solar cells. Mater Sci Eng 2015;193:181-8.

24. Diallo A, Beye AC, Doyle TB, Park E, Maaza M. Green synthesis of $\mathrm{CO}_{3} \mathrm{O}_{4}$ nanoparticles via Aspalathus linearis: Physical properties. Green Chem Lett Rev 2015;8:3-4, 30-6.

25. Upadhyay RK, Soin N, Bhattacharya G, Saha S, Barman A, Roy SS. Grape extract assisted green synthesis of reduced graphene oxide for water treatment application. Mater Lett 2015;160:355-8.

26. Maddinedi SB, Mandal BK, Vankayala R, Kalluru P, Pamanji SR. Bioinspired reduced graphene oxide nanosheets using Terminalia chebula seeds extract. Spectrochim Acta A Mol Biomol Spectrosc 2015;145:117-24.

27. Khan MY, Mangrich AS, Schultz J, Grasel FS, Mattoso N, Mosca $\mathrm{DH}$. Green chemistry preparation of superparamagnetic nanoparticles containing $\mathrm{Fe}_{3} \mathrm{O}_{4}$ cores in biochar. J Anal Appl Pyrolysis 2015;116:42-8.

28. Ehrampoush MH, Miria M, Salmani MH, Mahvi AH. Cadmium removal from aqueous solution by green synthesis iron oxide nanoparticles with tangerine peel extract. J Environ Health Sci Eng 2015;13:84.

29. Latha N, Gowri M. Bio synthesis and characterisation of $\mathrm{Fe}_{3} \mathrm{O}_{4}$ nanoparticles using Caricaya papaya Leaves extract. Int J Sci Res 2014; $12: 17$

30. Maensiri S, Laokul P, Klinkaewnarong J, Phokha S, Promarak V, Seraphin S. Indium oxide $\left(\mathrm{In}_{2} \mathrm{O}_{3}\right)$ nanoparticles using Aloe vera plant extract: Synthesis and optical properties. J Optoelectron Adv Mater 2008;10:161-5.

31. Awwad AM, Ahmad AL. Biosynthesis, characterization, and optical properties of magnesium hydroxide and oxide nanoflakes using Citrus limon leaf extract. Arab J Phys Chem 2014;2:65-70.

32. Moorthy SK, Ashok CH, Rao KV, Viswanathan C. Synthesis and characterization of $\mathrm{M}_{\mathrm{g}}$ Onanoparticles by neem leaves through green method. Mater Today P̈roc 2015;2(9):4360-8.

33. Srivastava V, Sharma YC, Sillanpä M. Green synthesis of magnesium oxide nanoflower and its application for the removal of divalent metallic species from synthetic wastewater. Ceram Int 2015;41(5):6702-9.

34. Kannan SK, Sundrarajan M. Green synthesis of ruthenium oxide nanoparticles: Characterization and its antibacterial activity. Adv Powder Technol 2015;26(6):1505-11.

35. Jayaseelan C, Rahuman AA, Roopan SM, Kirthi AV, Venkatesan J, Kim SK, et al. Biological approach to synthesize TiO2 nanoparticles using Aeromonas hydrophila and its antibacterial activity. Spectrochim Acta A Mol Biomol Spectrosc 2013;107:82-9.

36. Subhashini D, Nachiyar SV. Albizia saman: A green route for the reduction of bulk $\mathrm{TiO}_{2}$. Int J Chemtech Res 2014;6:5137-41.

37. Naik GK, Mishra PM, Parida K. Green synthesis of Au/TiO for effective dye degradation in aqueous system. Chem Eng J 2013;229:492-7.

38. Kumar PS, Francis AP, Devasena T. Comparative studies on green synthesized and chemically synthesized titanium oxide nanoparticles: A validation for green synthesis protocol using hibiscus flower. J Environ Nanotechnol 2014;3(4):78-85.

39. Sundrarajan M, Gowri S. Green synthesis of titanium dioxide nanoparticles by Nyctanthes arbor-tristis Leaves extract. Chalcogenide Lett 2011;8(8):447-51.

40. Sivaraj R, Rahman PK, Rajiv P, Narendhran S, Venckatesh R. Biosynthesis and characterization of Acalypha indica mediated copper oxide nanoparticles and evaluation of its antimicrobial and anticancer activity. Spectrochim Acta A Mol Biomol Spectrosc 2014;129:255-8.
41. Gunalan S, Sivaraj R, Venckatesh R. Aloe barbadensis Miller mediated green synthesis of mono-disperse copper oxide nanoparticles: Optical properties. Spectrochim Acta A Mol Biomol Spectrosc 2012;97:1140-4.

42. Kumar B, Smita K, Cumbal L, Debut A, Angulo Y. Biofabrication of copper oxide nanoparticles using Andean blackberry (Rubus glaucus Benth.) fruit and leaf. J Saudi Chem Soc 2015;30:30.

43. Sharma JK, Akhtar MS, Ameen S, Srivastava P, Singh G. Green synthesis of $\mathrm{CuO}$ nanoparticles with leaf extract of Calotropis gigantea and its dye-sensitized solar cells applications. J Alloys Compd 2015;632:321-5.

44. Mohan S, Singh Y, Verma DK, Hasan SH. Synthesis of CuO nanoparticles through green route using Citrus limon juice and its application as nanosorbent for Cr (VI) remediation: Process optimization with RSM and ANN-GA based model. Process Saf Environ Prot 2015;96:156-66.

45. Nasrollahzadeh M, Sajadi SM, Rostami-Vartooni A. Green synthesis of $\mathrm{CuO}$ nanoparticles by aqueous extract of Anthemis nobilis flowers and their catalytic activity for the $\mathrm{A}^{3}$ coupling reaction. J Colloid Interface Sci 2015;459:183-8.

46. Nasrollahzadeh M, Maham M, Sajadi SM. Green synthesis of $\mathrm{CuO}$ nanoparticles by aqueous extract of Gundelia tournefortii and evaluation of their catalytic activity for the synthesis of N-monosubstituted ureas and reduction of 4-nitrophenol. J Colloid Interface Sci 2015;455:245-53.

47. Nethravathi PC, Kumar MA, Suresh D, Lingaraju K, Rajanaika H, Nagabhushana $\mathrm{H}$, et al. Tinospora cordifolia mediated facile green synthesis of cupric oxide nanoparticles and their photocatalytic, antioxidant and antibacterial properties. Mater Sci Semicond Process $2015 \cdot 33: 81-8$

48. Nasrollahzadeh M, Sajadi SM, Rostami-Vartooni A, Bagherzadeh M, Safari R. Immobilization of copper nanoparticles on perlite: Green synthesis, characterization and catalytic activity on aqueous reduction of 4-nitrophenol. J Mol Catal A Chem 2015;400:22-30.

49. Sivaraj R, Rahman PK, Rajiv P, Salam HA, Venckatesh R. Biogenic copper oxide nanoparticles synthesis using Tabernaemontana divaricate leaf extract and its antibacterial activity against urinary tract pathogen. Spectrochim Acta A Mol Biomol Spectrosc 2014;133:178-81.

50. Nasrollahzadeh M, Sajadi SM, Rostami-Vartooni A, Bagherzadeh M. Green synthesis of $\mathrm{Pd} / \mathrm{CuO}$ nanoparticles by Theobroma cacao $\mathrm{L}$. seeds extract and their catalytic performance for the reduction of 4-nitrophenol and phosphine-free Heck coupling reaction under aerobic conditions. J Colloid Interface Sci 2015;448:106-13.

51. Anbuvannan M, Ramesh M, Viruthagiri G, Shanmugam N, Kannadasan N. Anisochilus carnosus leaf extract mediated synthesis of zinc oxide nanoparticles for antibacterial and photocatalytic activities. Mater Sci Semicond Process 2015;39:621-8.

52. Suresh D, Shobharani RM, Nethravathi PC, Pavan Kumar MA, Nagabhushana H, Sharma SC. Artocarpus gomezianus aided green synthesis of $\mathrm{ZnO}$ nanoparticles: Luminescence, photocatalytic and antioxidant properties. Spectrochim Acta A Mol Biomol Spectrosc 2015;141:128-34.

53. Divyapriya S, Sowmia C, Sasikala S. Synthesis of zinc oxide nanoparticles and antimicrobial activity of Murraya koeniggii. World J Pharm Pharm Sci 2014;3(12):1635-45.

54. Nethravathi PC, Shruthi GS, Suresh D, Nagabhushana H, Sharma SC. Garcinia xanthochymus mediated green synthesis of $\mathrm{ZnO}$ nanoparticles: Photoluminescence, photocatalytic and antioxidant activity studies. Ceram Int 2015;41:8680-7.

55. Senthilkumar SR, Sivakumar T. Green tea (Camellia sinensis) mediated synthesis of zinc oxide $(\mathrm{ZnO})$ nanoparticles and studies on their antimicrobial activities. Int J Pharm Pharm Sci 2014;6(6):461-5.

56. Elumalai K, Velmurugan S, Ravi S, Kathiravan V, Ashokkumar S. Retracted: Green synthesis of zinc oxide nanoparticles using Moringa oleifera leaf extract and evaluation of its antimicrobial activity. Spectrochim Acta A Mol Biomol Spectrosc 2015;143:158-64.

57. Fu L, Fu Z. Plectranthus amboinicus leaf extract-assisted biosynthesis of $\mathrm{ZnO}$ nanoparticles and their photocatalytic activity. Ceram Int 2015;41(2):2492-6.

58. Samat NA, Nor RM. Sol-gel synthesis of zinc oxide nanoparticles using Citrus aurantifolia extracts. Ceram Int 2013;39(1):S545-8. 